\title{
Industry Sectors And The Export Base Determination Of Nonmetropolitan Employment Change In Four Midwestern States
}

\author{
Curtis BRaschler and John A. Kuehn*
}

Identification and quantification of industrial sectors which stimulate rural regional growth constitute important inputs to policy formation. Rural industrialization has received emphasis in both legislation and development programs. Yet there is less than complete agreement concerning the importance of manufacturing in relation to other industrial sectors for changing overall levels of employment and economic activity in rural areas. An oft-heard criticism of rural industrialization is that much of the manufacturing sector exhibits slow-growth characteristics and that much of the service-oriented sector exhibits fast-growth characteristics. Manufacturing's proportion of total national employment has been about 25 percent for the past ten years. The national economy is rapidly becoming more oriented to industries like communications, wholesale and retail trades, personal services, recreation, business services, public administration, and education. In other words, criticism against rural industrialization hypothesizes that service-oriented industries, not manufacturing, constitute the primary source of both national and regional employment growth.

The objective of this research was to test statistically the relative importance of various industrial sectors in explaining rural employment growth in the four midwestern states of Arkansas, Kansas, Missouri, and Oklahoma. Data were obtained from the U.S. Censuses of Population for 1950, 1960, and 1970. Statistical tests were developed within the context of the economic base theory of regional growth. Williamson's recent review concluded that this theory can provide valid empirical predictions of regional growth.

\section{SOME RECENT STUDIES}

The extent of the literature relative to the subject of this paper is voluminous. Thus, no attempt will be made to develop an exhaustive review of all studies. However, some important ones will be reviewed in order: to provide some context for an appraisal of the empirical results reported herein.

\footnotetext{
*Respectively, Professor, Department of Agricultural Economics, University of MissouriColumbia, and Economist, Economic Development Division, Economic Research Service, U.S. Department of Agriculture. Contribution from the Missouri Agricultural Experiment Station Journal Series Number 7787.
} 
Hoyt has long been associated with the theoretical and empirical development of economic base analysis as a tool for measuring forces which affect the magnitude of regional growth and change. He argues in a 1969 paper that growth of manufacturing employment was a key variable in the population growth of many metropolitan regions of the U.S. from 1960 to 1967. Wendt and Varian used Hoyt's data along with a statistical analysis to dispute his conclusions in a paper in the same journal in August of 1970. Braschler, using a Missouri sample of counties, developed some simple regression equations suggesting a strong relation between change in manufacturing and change in total employment (Braschler, 1971).

Manufacturing has played a vital role in the revival of population growth in nonmetropolitan America. Beale reported that from 1962 to 1969 half of all nonmetro job growth in the nation was in manufacturing and that only since then have trades and services become more important. Economic base theory predicts that nonbasic trades and services should expand after basic activities like manufacturing expand. Kuehn's study of employment growth in the four-state area during the 1960's indicated that many nonmetro counties grew faster than the nation and that 296 of 372 counties had increased their shares of the nation's manufacturing employment.

\section{THE MODEL}

This study makes use of an empirical technique developed for determining multiplier relationships between the basic or export components and the total nonbasic employment of the local economy. The export base of each county area was determined by use of a procedure termed the group average requirements method (Braschler, 1971, 1973). This method is an adaptation of the location quotient method which uses national average industry employment as a criterion for determining local and export employment components. The group average requirement procedure involves first the grouping of counties (or other spatial units of observation) into two or more groups based upon a size criteria. Several groupings of the 339 nonmetropolitan counties were initially tried in the development stages of the study and these groupings were all based on size of the counties as measured by 1970 population. Statistical estimation of employment multipliers was improved by grouping county observations. Final groupings were determined by the application of statistical tests developed by Chow to various preliminary regression analyses. Two groupings were used for nonmetropolitan counties in the four state area. Group 1 included 249 counties with 1970 population sizes less than 20,000. Group 2 included 90 counties with 1970 population sizes greater than or equal to 20,000 .

For each grouping of counties and for each decade, 1950-60 and 196070 , regression equations were estimated wherein the decade change in 
total nonbasic employment was a function of the decade changes in basic employment for each of ten industries.

That is:

(1) $\quad \Delta$ N.B.E. $._{\cdot j}=b_{o}+b_{1} \Delta$ B.E. $\cdot{ }_{\cdot j}+\ldots+b_{10} \Delta$ B.E.10j $+e_{j}$

where

$\Delta$ N.B.E. $. j=$ Decade change in total nonbasic employment, for county $\mathrm{j}$.

$\Delta$ B.E. $_{\mathrm{ij}}=$ Decade change in basic employment in industry $\mathrm{i}$, county $\mathrm{j}$.

$b_{i} \quad=$ estimated regression coefficients.

$\mathbf{e}_{\mathbf{j}} \quad=$ estimated error term.

All employment in 1950, 1960, and 1970, in agriculture, mining, armed forces, and manufacturing was defined to be basic employment. Employment in each of the remaining six industries was divided into basic and nonbasic employment using the group average method developed by Braschler (1972). That is, for each of the three years and for each group separately:

$$
\text { B.E. } ._{i j}=E_{i j}-\left(\frac{\sum_{j} E_{i j}}{\sum \underset{i}{\sum} E_{i j}}\right) \quad \sum_{i} E_{i j}
$$

with the restriction that if:

$$
\text { B.E. } . \text { ij }<0 \text {, then B.E. }{ }_{i j}=0
$$

where:

B.E. $._{\text {ij }}=$ basic employment in industry i for county $\mathrm{j}$.

$\mathrm{E}_{\mathrm{ij}} \quad=$ total employment in industry $\mathrm{i}$ for county $\mathrm{j}$.

$1 \quad=1 \ldots 10$ industries.

j $\quad=1 \ldots \mathrm{n}$ counties in the group analyzed.

The division enclosed within parentheses is the group's average employment in industry i. And lastly,

$$
\text { N.B.E. } . j=\sum_{i} E_{i j}-\sum_{i}^{\Sigma} \text { B.E. } \cdot . j .
$$

To determine the relative importance of independent variables in regression functions, Harp has proposed the usage of marginal $\mathrm{R}^{2}$ and partial $\mathrm{r}^{2}$ (Harp, Theil). In our model, marginal $\mathrm{R}^{2}$ measures the increase 
in the total explained variation accounted for by the $\mathrm{i}^{\text {th }}$ industry given that the other nine industries have already been included in the regression equation. Partial $\mathrm{r}^{2}$ measures the proportion of variation unexplained by nine industries which is explained by the addition of industry $i$. Whereas partial $\mathrm{r}^{2}$ shows the percentage each industry reduces the total unexplained variance, marginal $\mathrm{R}^{2}$ shows the percentage each industry explains of total variance.

\section{STATISTICAL RESULTS}

This study was designed to identify the major industries stimulating growth in nonmetropolitan counties in four midwestern states and to determine any changes in the industries' relative importance. Tables 1 and 2 present the coefficients, their $t$ value, marginal $R^{2}$, and partial $r^{2}$. For group 1 counties of less than 20,000 population, manufacturing was the most important industry and agriculture the second most important industry in both decades. Insofar as basic employment in agriculture declined for the group overall, basic employment in manufacturing became the key industry in group 1 counties. Basic employment in the service industries became slightly more important for group 1 counties during the 1960's. Findings for group 2 counties of 20,000 or more population were similar to those of group 1 counties with only one major exception. Basic employment in the armed forces was also a major source of growth in both decades.

The results of the regression analysis of the data for both group 1 and group 2 counties were generally consistent with the theoretical framework of the study. However, several parts of the empirical analysis require further explanation. It is noted that several regression coefficients for group 1 counties for the 1950-60 time periods were negative. Of course, this is not consistent with theoretical expectations. Most of the negative regression coefficients were not significant at the usual 5 percent level. However, this apparent inconsistency can be rationalized by reviewing the economic conditions which existed in these rural counties during the decade from 1950 to 1960 . This was a period when the major basic industry (agriculture) was experiencing a substantial decline in employment with consequent secondary pressures on the service industries of these rural counties. Most of the service sectors of these counties thus had substantial excess capacity which only gradually was dissipated through the attrition of the existing capital facilities. Thus the negative regression coefficients for the basic components of mainly service industries in group 1 counties may reflect the lagged response of these industries to decline in employment of the major basic industry, agriculture.

The argument developed above is also buttressed by examining the statistical results for group 1 counties for the 1960 to 1970 period (Table 1). All regression coefficients become positive during this period and the multiple coefficient of determination improved from .47 to .67 (Table 1). 
TABLE 1 Regression Analysis of Group 1 Counties 1950-70

\begin{tabular}{|c|c|c|c|c|c|c|c|c|}
\hline \multirow[b]{2}{*}{ Industry } & \multicolumn{4}{|c|}{$1950-60$} & \multicolumn{4}{|c|}{$1960-70$} \\
\hline & $\begin{array}{l}\text { Regr. } \\
\text { Coeff. }\end{array}$ & $\begin{array}{c}t \\
\text { Value }\end{array}$ & $\underset{\text { R2 }}{\text { Marginal }}$ & $\begin{array}{c}\text { Partial } \\
\mathbf{x}^{2}\end{array}$ & $\begin{array}{l}\text { Regr. } \\
\text { Coeff. }\end{array}$ & $\begin{array}{c}t \\
\text { Value }\end{array}$ & $\underset{\mathbf{R}^{2}}{\text { Marginal }}$ & $\underset{\mathbf{r}^{2}}{\text { Partial }}$ \\
\hline $\begin{array}{l}\text { Agriculture, Forestry, } \\
\text { \& Fisheries }\end{array}$ & 0.26 & 6.4 & .10 & .16 & 0.91 & 14.1 & .28 & .46 \\
\hline Mining & 1.01 & 6.3 & .09 & .14 & 1.20 & 8.6 & .11 & .20 \\
\hline Armed Forces & 0.55 & 4.6 & .05 & .09 & 1.08 & 8.6 & .11 & .20 \\
\hline Manufacturing & 0.80 & 7.5 & .13 & .20 & 1.50 & 19.2 & .52 & .61 \\
\hline \multicolumn{8}{|l|}{ Transportation \& } & .08 \\
\hline Wholesale \& Retail Trade & -0.34 & -2.2 & .01 & .02 & 0.95 & 6.1 & .06 & .15 \\
\hline Private Business Services & -0.34 & -1.8 & .01 & .02 & 1.03 & 6.1 & .06 & .15 \\
\hline Education Services & 0.50 & 2.2 & .01 & .02 & 1.04 & 6.6 & .07 & .18 \\
\hline Public Administration & -0.33 & -0.9 & .00 & .00 & 1.22 & 4.2 & .03 & .08 \\
\hline \multirow[t]{3}{*}{ Construction } & 0.08 & 0.5 & .00 & .00 & 0.67 & 3.9 & .04 & .11 \\
\hline & \multicolumn{4}{|c|}{$\mathrm{N}=249$} & \multicolumn{4}{|c|}{$\mathrm{N}=249$} \\
\hline & \multicolumn{4}{|c|}{$\mathrm{R}^{2}=.47$} & \multicolumn{4}{|c|}{$\mathrm{R}^{2}=.67$} \\
\hline
\end{tabular}


TABLE 2. Regression Analysis of Group 2 Counties 1950-70

\begin{tabular}{|c|c|c|c|c|c|c|c|c|}
\hline \multirow[b]{2}{*}{ Industry } & \multicolumn{4}{|c|}{$1950-60$} & \multicolumn{4}{|c|}{$1960-70$} \\
\hline & $\begin{array}{l}\text { Regr. } \\
\text { Coeff. }\end{array}$ & $\begin{array}{c}t \\
\text { Value }\end{array}$ & $\underset{\mathrm{R}^{2}}{\text { Marginal }}$ & $\underset{\mathbf{r}^{2}}{\text { Partial }}$ & $\begin{array}{l}\text { Regr. } \\
\text { Coeff. }\end{array}$ & $\begin{array}{c}\mathbf{t} \\
\text { Value }\end{array}$ & $\underset{\mathrm{R}^{2}}{\text { Marginal }}$ & $\underset{\mathbf{r}^{2}}{\text { Partial }}$ \\
\hline $\begin{array}{l}\text { Agriculture, Forestry, } \\
\text { \& Fisheries }\end{array}$ & 0.97 & 10.4 & .08 & .57 & 1.82 & 14.7 & .32 & .73 \\
\hline Mining & 1.14 & 4.8 & .02 & .25 & 1.87 & 8.1 & .10 & .45 \\
\hline Armed Forces & 1.03 & 13.6 & .13 & .68 & 1.71 & 14.2 & .30 & .71 \\
\hline Manufacturing & 1.17 & 8.9 & .06 & .50 & 1.90 & 15.0 & .34 & .74 \\
\hline $\begin{array}{l}\text { Transportation \& } \\
\quad \text { Communication }\end{array}$ & 1.58 & 4.1 & .01 & .14 & 1.55 & 3.4 & .02 & .14 \\
\hline Wholesale \& Retail Trade & -0.50 & 1.7 & .01 & .14 & 2.24 & 6.2 & .06 & .33 \\
\hline Private Business Services & 1.54 & 3.9 & .02 & .25 & 1.58 & 4.8 & .03 & .20 \\
\hline Education Services & 1.33 & 6.0 & .03 & .33 & 1.21 & 7.7 & .09 & .43 \\
\hline Public Administration & 1.07 & 2.5 & .01 & .14 & 2.14 & 6.4 & .06 & .33 \\
\hline Construction & 0.13 & 0.4 & .00 & .00 & -0.50 & -1.0 & .00 & .00 \\
\hline & & $\begin{array}{l}\mathrm{N} \\
\mathrm{R}^{2}\end{array}$ & $\begin{array}{l}90 \\
.94\end{array}$ & & & & $\begin{array}{l}\mathbf{N}= \\
\mathbf{R}^{2}=\end{array}$ & \\
\hline
\end{tabular}


It will be recalled that rural areas of the Midwest experienced a substantial turn-around from one of fairly general decline (1950-60) to one of stabilization and in many cases growth in employment and economic activity from 1960 to 1970 .

The model provided a substantially better predictor of change in service employment in the group 2 counties than in the group 1 counties as measured by the multiple coefficients of determination (compare Tables 1 and 2). Again this appears consistent with the lagged response to economic decline hypothesis developed above. The group 2 counties were mostly growth areas in the region during both decades. The results of the statistical analysis are consistent with the logic of the lagged response to decline hypothesis in the sense that service industries would theoretically respond to increases in demand for their output by adding new employees and increasing capital facilities once the earlier excess capacity was exceeded. This is reflected by the substantial improvement in the measure of variation explained by the model for group 2 counties as compared to group 1 counties.

Finally, it is argued that the model was constructed and tested using time difference data primarily to obtain a better understanding of the industries to which change in economic activity could be primarily attributed. Given the large time differences and lagged response hypothesis to decline, the statistical analysis provides a respectable basis for attributing change in economic activity primarily to the change in manufacturing.

The service employment multipliers (regression coefficients) increased substantially in size for both county groupings from 1960 to 1970 as compared to the values for the 1950 to 1960 period (Tables 1 and 2). This is consistent with existing hypotheses regarding the shift of the United States economy to a service orientation. As the service components of the local economies increase in relative importance through time, the multiplier impact of basic industries can be expected to increase through time.

\section{POLICY IMPLICATIONS}

Manufacturing appears to be the key industry in stimulating growth in brth group 1 and group 2 counties as noted by marginal $\mathrm{R}^{2}$ and partial $\mathrm{r}^{2}$. As such, rural industrialization programs could offer a viable path to growth for these Midwestern, rural counties. Basic employment in the service industries became only slightly more important during the 1960's than during the 1950's. Future changes in the spatial distribution of employment and population will likely continue to depend upon changes primarily in manufacturing location. 


\section{REFERENCES}

Beale, Calvin L. The Revival of Population Growth in Nonmetropolitan America, ERS605, Washington: U.S. Department of Agriculture, June 1975.

Braschler, Curtis, "A Comparison of LeastSquares Estimates of Regional Employment Multipliers with Other Methods," Journal of Regional Science, Volume 12, No. 3, 1972, pp. 457-468.

Braschler, Curtis, "Importance of Manufacturing in Area Economic Growth," Land Economics, Volume XLVII, No. 1, February 1971, pp. 109-111.

Braschler, Curtis, "Regional Growth Model An Analytical Approach in Missouri 1950 to 1970," UMC Agricultural Experiment Station Research Bulletin 996, March 1973.

Chow, Gregory C. "Tests of Equality of Coefficients between Sets of Coefficients in Two Linear Regressions," Econometrica, Vol. 28, 1960, pp. 591-605.
Harp, Harry H., "Use of Marginal R2 and Partial $\mathrm{r}^{2}$ in a Multiple Regression Analysis,". Agricultural Economics Research, Vol. 19, No. 4, October 1967, pp. 103-110.

Hoyt, Homer, "Importance of Manufacturing in Basic Employment," Land Economics, Volume XLV, No. 3, August 1969, pp. 344-349.

Kuehn, John A., Employment Growth in the Ozark States, 1960-1970, Agricultural Economics Report No. 269, Washington: U.S. Department of Agriculture, Nov. 1974.

Theil, Henri, Principles of Econometrics, John Wiley and Sons, Inc., 1971, pp. 167-175.

Wendt, Paul F. and Varian, Hal R., "A Note on Hoyt's Importance of Manufacturing in Basic Employment," Land Economics, Volume XLVI, No. 3, August 1970, pp. 350-354.

Williamson, Robert B., "Predictive Power of the Export Base Theory," Growth and Change, Volume 6, No. 1, January 1975, pp. 3-10. 